\title{
Debate e Investigación El Patrimonio histórico industrial y la revitalización urbana y económica de Bilbao
}

Joseba Juaristi

Catedrático de Geografia Humana.Universidad del País Vasco

En este artículo nos proponemos mostrar el papel que tiene actualmente el patrimonio histórico industrial en la revitalización urbana del área metropolitana de Bilbao. El estilo de desarrollo urbano de esta urbe, iniciado en la década de los años 90 , ha sido popularizado a través de la imagen del edificio del museo Guggenheim, símbolo de la renovación de Bilbao. Dicha renovación se está llevando a cabo a través de la urbanización de la zona de Abandoibarra, mediante la creación de un patrimonio inmobiliario que incluye arquitectura de vanguardia y prestigio. Las acciones urbanizadoras en este entorno han dado lugar a un contexto en el cual los elementos industriales de un pasado reciente (espacios, infraestructuras, edificios, artefactos singulares) pueden incorporarse al patrimonio de diferentes formas: como creación de equipamientos culturales (museos temáticos), como adaptaciones para nuevos usos de antiguas áreas mineras e industriales, con la intervención en artefactos industriales en desuso produciendo una museización de los mismos, 0 simplemente como ruinas, con una prolongación estudiada de su abandono y el decaimiento, de acuerdo con criterios estéticos postmodernos.

\section{Palabras clave}

\section{Patrimonio industrial}

Desarrollo socioeconómico

Abandoibarra

\section{Bilbao}

País Vasco

Áreas urbanas

Museo Guggenheim

Ordenación del territorio

\section{El capital simbólico y la fabricación del contexto}

Las preocupaciones públicas por la revitalización económica y urbana de Bilbao comienzan a manifestarse en los años 80, a causa de la crisis económica que afecta de modo especial a la industria siderúrgica, y a sus consecuencias: cierre de fábricas, desempleo, falta de alternativas económicas, etc. En esos años la planificación urbana se realiza aún sobre una escala municipal (planes generales de ordenación urbana), y el único organismo de planificación metropolitano existente entonces, la Corporación Administrativa del Gran Bilbao, se muestra inoperante por la falta de interés que muestran las instituciones participantes: los ayuntamientos del área metropolitana, y los representantes del Estado. Los escasos recursos con que contaba esta corporación son transferidos al Gobierno Vasco.

También es en estos años cuando comienza lo que podríamos llamar la aventura de Abandoibarra. Abandoibarra es una extensa superficie en la ribera izquierda de la ría justo al pie del pequeño escarpe de la terraza fluvial en la que se encuentra el Ensanche de Bilbao, planificado en 1876 tras la anexión a Bilbao del municipio de Abando. Los terrenos de este lugar debieron ser utilizados en tiempo inmemorial como huertas (ibarra en euskera equivale a vega), aunque la memoria de los bilbainos lo recuerda más como espacio portuario, con tinglados de astilleros de ribera y talleres. A comienzos del siglo XX se instala en la mitad occidental de estos terrenos la factoría Euskalduna de construcción naval.

La reconversión industrial llevó consigo el cierre de muchas fábricas y empresas, entre ellas la de los astilleros Euskalduna en la década de los años ochenta. Este cierre estuvo precedido por numerosas jornadas de protesta de los trabajadores que cortaban el acceso a Bilbao en el puente de Deusto, contiguo a la factoría. Hubo algunas jornadas de enfrentamientos con la policía, recordadas después como las "batallas del puente de Deusto". A estas jornadas sucedieron otras en las cuales los trabajadores del astillero llevaban a cabo un cierre ritual no violento del puente con barricadas de diferentes estilos y materiales (madera, mecanotubo, etc.) que mostraban la habilidad e ingenio de los trabajadores. Eran manifestaciones que reflejaban el funcionamiento del capital simbólico en épocas de crisis. Como intentaremos explicar más adelante, el capital simbólico es un concepto que nos puede ayudar a entender la transformación de Bilbao y la creación de un nuevo contexto.

Abandoibarra había quedado señalada como una zona "emblemática" dentro del Plan General de Ordenación Urbana de Bilbao (1985-1994), por su localización junto al Ensanche y por disponer de abundante suelo que quedaba vacante, y fue objeto de un Plan Especial de Reforma Interior. Una de las acciones de este Plan fue la realización de un concurso de ideas sobre Abandoi- 


\section{$080-081$}

\section{Debate}

\section{e Investigación}

El Patrimonio histórico

industrial y la revitalización

urbana y económica

de Bilbao

\section{PH42 - Febrero 2003}

barra y el establecimiento de contactos con urbanistas expertos, entre ellos el arquitecto Cesar Pelli, actual responsable del diseño de este espacio.

De esta etapa de planificación municipal se pasa a otra en la cual toman protagonismo dos asociaciones que impulsan la regeneración urbana y económica de Bilbao desde una escala metropolitana, dentro de los planteamientos propios de la planificación estratégica. Una de estas asociaciones es la llamada Bilbao Metrópoli 30, creada en 1991, que tiene la función de un lobby, tratando de comprometer a empresas privadas, instituciones públicas, y diferentes agentes sociales en las tareas de regeneración. Los planes estratégicos que elabora esta asociación sólo valen para reflejar logros y manifestar aspiraciones, ya que como institución carece de poder ejecutivo. La segunda asociación es la sociedad anónima de capital público Bilbao-Ría 2000, constituida a partes iguales por la administración pública del estado (a través del ministerio de Fomento) y por las administraciones vascas (autonómica, provincial y los dos ayuntamientos más populosos del área metropolitana: Bilbao y Barakaldo). Bilbao-Ría 2000 realiza las gestiones necesarias para proporcionar suelo y llevar a cabo planes de urbanización mediante actuaciones definidas. Esta sociedad fue creada en noviembre de 1992.

Entre las ideas sobre renovación urbana que manejaban los responsables de la política local, a finales de los años ochenta, estaba la renovación de la imagen urbana a través de la incorporación de arquitectura de prestigio en nuevos edificios e infraestructuras públicas. El Plan General de Ordenación Urbana de Bilbao proponía entonces modestamente "algún edificio emblemático" en el Ensanche, y uno de los primeros proyectos de nueva infraestructura de transportes, la Estación Intermodal de Abando fue encargado a los arquitectos ingleses James Stirling y Michael Wilford. Otro proyecto de los años ochenta fue la creación de una gran infraestructura cultural que iba a estar ubicada en un edificio de grandes proporciones (un cubo de cristal de ochenta metros de arista), diseñado por el arquitecto Francisco Saénz de Oiza según ideas del escultor Jorge Oteiza. También en esta década se encarga el diseño de las estaciones del metro de Bilbao al arquitecto Norman Foster.

Si bien la década de los años ochenta es la de los proyectos, la de los noventa va a ser la de las realizaciones. Algunos proyectos quedarán rechazados definitivamente (el "cubo" de Oteiza), otros demorados indefinidamente (la estación intermodal), y otros verán felizmente la luz, como el metro de Bilbao, inaugurado en 1995.

Sin embargo es ampliamente conocido que el arranque de lo que podría llamarse el modo bilbaíno de desarrollo estratégico se produce con la construcción del edificio del museo de la Fundación Guggenheim, según el diseño del arquitecto Frank Gehry. Este "modo bilbaíno" ha sido ejemplarizado con la culminación de las negociaciones entre el Gobierno Vasco y la Fundación Guggenheim el año 1992, y simbolizado por la escena que se desarrolla en Febrero del mismo año en la bolsa de Wall Street en la cual José Antonio Ardanza, presidente entonces del Gobierno Vasco, entrega a la Fundación Guggenheim un cheque por valor de 20 millones de dólares. Un simbolismo similar tiene la presentación de la maqueta del edificio diseñado por Gehry en la Bolsa de Bilbao, en cuya entrada los asistentes al acto tienen que soportar los gritos de protesta de los trabajadores de Altos Hornos de Vizcaya, que piden

\section{Opinión del lector}

Patrimonio:

vía de desarrollo económico y social

$M^{\underline{a}}$ Teresa Suárez Domínguez

Historiadora del Arte, especializada en Museos y Patrimonio

El patrimonio de cada localidad es nuestra riqueza más inmediata, un valor seguro que representa el potencial de gran parte del desarrollo económico y social.

El área de patrimonio es sin duda motor del desarrollo local en los últimos tiempos, estamos asistiendo a una lenta pero progresiva transformación en cuanto a la perspectiva y valoración del patrimonio en todo su conjunto (histórico, artístico, natural, etnográfico, etc.) que lo toma como eje vertebral de la econo- mia local pudiendo atraer nuevas vías de desarrollo conforme a las riquezas de cada lugar.

El turismo de calidad que se genera a partir de las características del patrimonio existente es un potencial económico que puede derivar en cambios sociales como nuevas profesiones para la población y enriquecimiento cultural y personal marcando así las señas de identidad de una población que vive y disfruta de sus bienes patrimoniales.

Es muy amplio el estudio que podría hacerse de cada zona ya que no son sólo los bienes tangibles los objetivos a difundir sino que la historia incluso hasta sin restos existentes en dicha localidad también constituye un pilar importante sobre el que instalar nuevas ideas que la difundan.

Tal es el caso del aún por estrenar "Museo de los Ingleses" de Punta Umbria (Huelva) que tiene en proyecto recoger todo el periodo que pasaron los ingleses, procedentes de las minas de Rio Tinto en su mayoria, en la hermosa localidad costera, sus 
"menos museos y más empleo" (Zulaika, 2001).

Estas escenas tenían mucho de apuesta arriesgada en un contexto económico negativo, y por ello han sido mostradas una y otra vez como ejemplo de lo que algún autor podría llamar "bingo-capitalismo" (Dear, 2000), o bien como un modo de juego de simulación por ordenador siguiendo el modelo del programa SIMCITYTM, como el ejemplo que presenta Edward Soja para Orange County en California (Soja, 2000). Por cierto, en las versiones más recientes de este juego es posible incorporar a las ciudades simuladas edificios "emblemáticos" de todo el mundo a través de Internet (¿estará ya disponible en la red el edificio de Gehry?).

La imagen de aldeanos apostando en el "casino de la globalización" (Zulaika, 2000) no es en absoluto lesiva para los lugareños. Se pueden encontrar en la literatura sobre planificación estratégica justificaciones teóricas según las cuales los métodos modernos de gestión deben adecuarse a los modos nacionales de hacer las cosas, a la cultura local (Bouinot y Bermils, 1995). La cultura local bilbaina no son los juegos de azar, como sucede en la ciudad de los casinos desde la que escribe Zulaika, sino el mus, un juego de envite que requiere coordinación y estrategia. En su momento la apuesta por el Guggenheim fue una entre varias, y de éstas hubo algunas fallidas, como los intentos de atraer nuevas industrias a través de proyectos empresariales. El éxito del Guggenheim se ha considerado también como el éxito de un modo de hacer las cosas. Este éxito está justificado, vistas las cosas a posteriori, por:

1. La utilización del capital simbólico para atraer voluntades y asumir riesgos. Esto supone que las decisiones de los gobernantes utilizando el monedero de los ciudadanos trascienden las evaluaciones económicas con métodos objetivos.

La fórmula del partenariado público-privado, tan repetida en los planes estratégicos, y que normalmente es entendida como "meter dinero público en empresas privadas" o "inversión pública/beneficio privado" encuentra su justificación porque el descontento popular con las decisiones politicas que afectan a los ciudadanos es canalizado a través del capital simbólico.

Los beneficios públicos (externalidades) que se hacen evidentes en algunas obras de infraestructura, como mejora de calles, paseos, parques, etc., no son tan claras en el caso de industrias culturales de carácter más elitista. En estos casos las industrias culturales pueden ser aceptadas mediante un valor de uso dual, popular y elitista a la vez, dividiendo el tiempo de uso: escenarios de la elite en unos momentos, de encuentros populares en otros.

2. El impacto novedoso de la regeneración urbana supone un nuevo contexto en el cual la presencia de ruinas del pasado es necesaria, no sólo como recurso estético, sino como medio para establecer la necesaria tensión pasado/presente que legitime y permita la continuidad del proceso.

No nos gustaría hacer una digresión larga sobre cuestiones teóricas, pero sí es conveniente aclarar algo el concepto de capital simbólico, concepto creado por el filósofo y antropólogo Pierre Bourdieu para estudiar las relaciones económicas de intercambio en sociedades agrarias con economías premonetarias (Bourdieu, 1977). Para este autor el capital simbólico (de una familia, o de una colectividad) no incluye sólo el patrimonio material, sino también su red de alianzas y clientelas, deudas de honor, prestigio, derechos y deberes, etc., que proporciona una fuente de fuerza adicional que puede ser utilizada cuando se producen situaciones extraordinarias que rompen la rutina.

En estrecha relación con el concepto de capital simbólico está la distinción de este autor de la división del tiempo (que él aplica a los ciclos agrícolas) en períodos de trabajo y períodos de producción. La trasposición de estos conceptos a los ciclos económicos capitalistas debe hacerse con prudencia, y puede parecer una contradicción exagerada el considerar las épocas de importantes pérdidas de empleo en la industria como "períodos de producción", aunque también es cierto que las pérdidas de empleo pueden estar motivadas por el incremento de la productividad debida a la aplicación de tecnología, o por otras innovaciones que suponen procesos de sustitución en el producto. En el caso de la regeneración de Bilbao el capital simbólico de los vizcainos, traducido primero en dólares, se transforma luego en un objeto material que es a su vez un fetiche de la postmodernidad y un talismán para la consecución de nuevos objetivos de revitalización.

Resulta difícil hablar de la revitalización de Bilbao sin nombrar el Guggenheim, pero quizá es mejor observar las consecuencias de este tipo de acciones en el plano del capital simbólico. Con respecto al primero de los puntos señalados arriba hay que ver el 


\section{$082-083$}

\section{Debate}

\section{e Investigación}

El Patrimonio histórico

industrial y la revitalización

urbana y económica

de Bilbao

\section{PH42 - Febrero 2003}

carácter elusivo a la valoración económica que ha tenido el museo. Ha habido críticas a la estética, al carácter "genérico" del edificio, no adaptado a la localidad (Casanelles, 1997), u otras referentes a que la fuerte inversión económica pudo tener otros destinos alternativos, críticas también a la rentabilidad electoral, etc., sin embargo, las valoraciones económicas que reflejan lo poco que ha cambiado la estructura productiva sectorial de Bizkaia a corto plazo (Esteban, 2000), han tenido poco eco, asi como la reclamación de que se midan estas acciones en términos de empleo (Gómez, 1998). También la Sociedad Bilbao-Metrópoli 30 ofrece regularmente las cifras del impacto: una media de cien mil visitantes al mes y cuatro mil empleos generados (directa e indirectamente) puede servir como media de los primeros cinco años de ejercicio (Bilbao-Metrópoli 30, 2002). Pero aun asi eso supone sólo una pequeña parte del "efecto Guggenheim". Parafraseando a Bourdieu: "Aquellos que aplican las categorias y métodos de la economía a las economias [postmodernas] sin tener en cuenta la transmutación ontológica que ellas imponen sobre su objeto están tratando hoy en día este tipo de economía como los Padres de la Iglesia trataron a las religiones que precedieron al cristianismo" (Bourdieu, 1977, 177).

Una consecuencia de ello es que en los "Informes de Progreso" que publica la Asociación Bilbao-Metrópoli 30 no hay referencias ni a la demografía, ni al empleo, ni al debate social. Se hacen oídos sordos al hecho de que, desde 1981 hasta el año 2001, el área metropolitana de Bilbao ha sufrido una pérdida de población de 56.000 habitantes. Si tenemos en cuenta que la planificación estratégica de ciudades debe tener en cuenta tanto la eficiencia como la equidad (Bouinot y Bermils, 1995), se pone en evidencia aquí que el "modo bilbaíno de planificación estratégica" está claramente sesgado hacia una planificación de tipo exclusivamente empresarial, primando la productividad por encima del empleo.

El museo Guggenheim ha marcado las pautas en la ulterior urbanización de Abandoibarra. El edificio, emplazado en el extremo oriental de estos terrenos, ha visto la construcción en el extremo occidental de otra infraestructura cultural: el Palacio Euskalduna dedicado a la música y congresos. Pero su efecto poderoso de creación de contexto, propio de la arquitectura y el urbanismo postmoderno (Ellin, 1996), se ha extendido también en la arquitectura de la ciudad de Bilbao: algunos edificios hacen guiños al museo, pero hay también un parentesco implícito del acero y cristal -utilizado en la construcción de las nuevas estaciones de RENFE- con el titanio del museo y con las bóvedas que cubren la entrada a las estaciones del metro: los llamados "fosteritos". Se ha producido también un contagio mimético en la renovación del Museo de Bellas Artes de Bilbao, un museo patrimonial que acoge una excelente pinacoteca, el cual ha sufrido una trasmutación apreciable en la ampliación de su edificio neoclásico, con un añadido funcionalista y una nueva reorganización interna, alterando la jerarquía del orden cronológico de la exposición de obras a favor de una presentación postmoderna: el museo no es un depósito de bienes del pasado, sino un lugar del presente, en el que simultáneamente se dan la tradición y la innovación (Walsh, 1992). De menor resonancia ha sido el surgimiento de algunas galerias de arte privadas próximas al Guggenheim, y también un equipamiento municipal: Bilbao Arte, con una sala de exposiciones de arte moderno situado en una an-

\section{Opinión del lector} Por un desarrollo patrimonial de calidad

Antonio David Bravo Carrasco Historiador

Francisco Javier Sánchez García Arqueólogo

Socios de la empresa Investigación y Desarrollo Arqueológico S.C.

Desde enfoques miopes y en ocasiones nada inocentes, se ha querido presentar el patrimonio histórico-cultural como una traba, un obstáculo para determinados modelos de crecimiento económico y formas de actuación privadas -y en ocasiones públicas- cuya implementación se identifica dogmáticamente con el "progreso".

Está visión descansa en un vulgar mercantilismo que desdeña todo aquello que tenga que ver con la cultura y la conciencia ciudadana, pues ésta a menudo supone cortapisas al desarrollo de intereses individuales de discutible utilidad colectiva.
La nuevas orientaciones venidas de la Unión Europea, el desarrollo de una creciente necesidad de servicios culturales y civicos dentro de lo que se ha dado en llamar "sociedad del ocio", las experiencias en curso en algunos lugares de Andalucia, etc. demuestran a las claras la posibilidad de generar valor añadido desde una política que combine la dimensión reflexiva y cívica del patrimonio con su adecuada inserción en el mercado.

En este sentido, el riquísimo patrimonio histórico-cultural andaluz (arqueologia, urbanismo, paisajes tradicionales, culturas tradicionales, historia social, etc.) puede desempeñar un rol protagónico en los nuevos esquemas de desarrollo rural que el campo andaluz necesita en un contexto de crisis del modelo de acumulación proteccionista promovido por la U.E y las administraciones españolas.

Así, el desarrollo de un turismo patrimonial de calidad, su sinergia con otros sectores como el turismo rural, la agricultura ecológica; la consecuente potenciación de las identidades civicas locales y de la imagen de los productos andaluces, pueden 
Foto 1: Casa de motobombas en Elorrieta, futura sede de un "Museo del agua"

tigua fábrica de harinas en el barrio de Bilbao la Vieja.

Es posible también atribuir al contagio mimético del Guggenheim la creación en Vitoria-Gasteiz del Artium, un museo de arte moderno. Estos "museos de primer nivel" han asociado su imagen, a través de la promoción turística del Gobierno Vasco, incluyendo el museo Chillida-Leku, propiedad de la familia de este escultor, emplazado en Hernani, creando así un circuito cuya explotación turística permitirá prolongar el número de días de estancia de los visitantes foráneos.

El segundo punto mencionado, la fabricación de un contexto, hay que verlo como un proceso que tiene su origen en los años 80, años en los que se dan las cifras más altas de paro, el cierre de fábricas y la desolación general ante la falta de alternativas. En esos años comienza a desarrollarse una estética narcisista de contemplación y melancolía de las ruinas industriales (y del deterioro urbano en general) que se refleja en su momento a través del arte fotográfico, la literatura local o la pintura. Es cierto que esta afirmación requiere un estudio más amplio de corrientes y vanguardias artísticas del momento, ya que no afirmamos una tendencia generalizada, pero pueden aportarse algunos ejemplos de este neorruinismo postindustrial: las fotografías sobre escenas y paisajes industriales de Pedro Zarrabeitia que aparecen en la exposición dedicada al centenario de la Cámara de Comercio de Bilbao, el año 1986, los cuadros de Jesús Mari Lazkano, un joven pintor que utiliza el realismo y la fuerza del paisaje de la cubeta de Bilbao, tomando elementos geográficos familiares, en mezclas oníricas con elementos alegóricos, y cuyo merecido éxito ha sido correspondido con adquisiciones y encargos públi- cos, o el poeta Iñaki Ezkerra, que lamenta la modernización de Bilbao, a la que prefiere recordar como una "Venecia pobre". La explotación estética de los contrastes y las contradicciones es uno de los recursos del arte, de la arquitectura y el urbanismo postmoderno, y como he escrito en otra ocasión (perdón por la autocita) se trata de una estrategia completa de "postmodernización" de la ciudad (Juaristi, 1999): la ruina se une a lo ultramoderno para explotar simbólicamente ese contraste. Creo que fue James Stirling -el arquitecto encargado del proyecto de la Estación Intermodal de Abando- quien manifestó, en una de sus primeras visitas a Bilbao que el punto fuerte de la ciudad era su "geografía". Stirling fue demasiado prudente, aunque una de las acepciones de "geografía" es la de "ese conjunto de cosas desordenadas que están ahí fuera y que dan carácter a un lugar".

Frank Gehry también debió estar muy comedido cuando dijo que "Bilbao tiene la estética de la realidad". El antropólogo Joseba Zulaika nos aclara que Frank Gehry aprendió a apreciar la "belleza dura" de Bilbao a partir de su amigo el escultor Richard Serra, bajo una posible influencia de la "estética de lo feo" del escultor vasco Jorge Oteiza (Zulaika, 2001). Gehry era consciente de la tensión que introducía el diseño de su edificio en este escenario, contraste que sin duda ha ayudado a realzar la fuerza del impacto. El mismo Gehry lamentó la pérdida de "contexto" que podría producirse con la urbanización de Abandoibarra y su entorno, de acuerdo con el proyecto de Pelli, y debido a la proliferación de edificios "emblemáticos" de arquitectos de renombre mundial: Krier, el mismo Pelli, Isozaki, Legorreta y otros, manifestando el arquitecto californiano su temor a que Bilbao se con- contribuir a un nuevo modelo social rural que apueste por la diversificación socioeconómica, la fijación de las nuevas generaciones en el tejido social de los pueblos, la conciencia crítica de las ciudadanias locales, sin por ello ir en demérito de políticas de desarrollo integrales que contemplen otros renglones productivos y ayudas o subvenciones transicionales a sectores sociales desfavorecidos (como los jornaleros, por ejemplo).

Como incipientes paradigmas de lo dicho, asistimos en los últimos años a la creación de iniciativas diversas que pretenden movilizar a las sociedades rurales andaluzas, demostrando sus posibilidades endógenas de crecimiento económico y cultural. Un caso paradigmático es el de Almedinilla, un pequeño pueblo de no más de 2500 habitantes, enclavado en la Subbética cordobesa. Desde el museo histórico local y en el marco de un proyecto de desarrollo integral centrado en la arqueología y los valores naturales (el ecomuseo del río Caicena) se ha procedido a la investigación y puesta en valor de dos yacimientos arqueológicos señeros, la villa romana del Ruedo y el poblado ibérico de Cerro de la Cruz. Interesantísimos hitos en la investigación científica, en virtud a las propuestas de difusión llevadas a término por el museo, han conseguido convertirse en vectores de desarrollo, atrayendo actualmente un caudal de visita cercano a las 15000 personas al año (sobre un total de habitantes de 2500 habitantes).

Este ejemplo en fase de consolidación nos muestra el tipo de rentabilidad no especulativa y más sostenible que nos propone el patrimonio histórico-cultural, aunque, evidentemente, todo proyecto de investigación y desarrollo de estas caracteristicas precisa de la implicación de los actores locales y de una financiación y gestión creativas, marcada por la fluidez administrativa (al socaire de las desmoralizantes trabas burocráticas) y la participación mesurada y debidamente supervisada de la iniciativa privada (tanto en financiación como en gestión).

De darse estos requisitos, y en el favorable contexto económico-politico que nos permiten bosquejar las politicas comunitarias, el futuro del patrimonio como bien social y económico será sin duda brillante para Andalucia. 


\section{$084-085$ \\ Debate \\ e Investigación}

El Patrimonio histórico

industrial y la revitalización

urbana y económica

de Bilbao

PH42 - Febrero 2003 vierta en "un parque temático de arquitectura".

Ciertamente la estética de la dureza de los paisajes industriales ya había sido recogida por pintores de generaciones anteriores, pero en esos momentos de crisis fue utilizada e introducida en un nuevo sistema de símbolos. No es nada raro que la Asociación Bilbao Metrópoli 30 organizara una exposición de fotografía, en el año 1993, con obras sobre Bilbao encargadas a autores como Gabriele Basilisco, John Vink, Carlos Cánovas, John Davies, Bruce Gilden y Carlos de Andrés. El catálogo de la exposición, titulada "Ría de Hierro", se publicó en tres idiomas (castellano, euskera, inglés), y con él se obsequiaba a las visitas distinguidas interesadas en la rehabilitación de Bilbao. En dicho catálogo, y a modo de disculpa, el comisario de la misma afirmaba: "No se trata,..., de una visión negativa de nuestro entorno, de decir "no hay salida", sino por el contrario, de buscar nuevos modos de relación con nuestro entorno" (Bilbao Metrópoli 30, 1993). Si Abandoibarra se está convirtiendo en un parque temático de arquitectura, el resto del valle de la ría de Bilbao necesitará mantener una estética de dureza. Ese es el secreto de la "bilbao beauty".

En este contexto, Abandoibarra está tomando la forma de un oasis de progreso en medio de la cubeta de Bilbao en la cual las ruinas industriales, y también las fábricas en funcionamiento aportan una estética de choque. En Abandoibarra ya se han plantado las primeras palmeras.

\section{Las alternativas de rehabilitación y regeneración}

Las ruinas industriales han sido vistas tanto como un problema como una oportunidad. Los problemas han sido sobre todo de orden ambiental: existencia de depósitos de pesticidas, vertederos, etc. Ello ha llevado a actuaciones de eliminación y tratamiento de pesticidas (ha sido necesaria la creación de una planta para el tratamiento de $\mathrm{HCH}$ en Barakaldo), y a la construcción de celdas de seguridad para almacenar pesticidas. Hay una celda de ese tipo ubicada justo debajo de la pista del aeropuerto de Loiu, y recientemente se ha inaugurado el sellado de otra celda en el monte Argalario, sobre un área de desmontes mineros. Existe en la margen derecha un centro comercial -Arteaconstruido también sobre un antiguo vertedero. Estos lugares han planteado, al menos ante la opinión pública, los problemas de la futura utilización de las superficies que se encuentran sobre las celdas, de cara a peligros potenciales.

Las primeras actuaciones de demolición de ruinas tuvieron un carácter simbólico, y se realizaron precisamente en Abandoibarra, teniendo como objeto los hangares de la factoría Euskalduna, el año 1992 (Esteban, 2000, 157). El Gobierno Vasco tiene un Programa de Demolición de Ruinas Industriales, que ha servido para poner en uso un total de 120 hectáreas, en 33 actuaciones, en el Bilbao Metropolitano. En el conjunto de la Comunidad Autónoma las actuaciones han sido 78, y la superficie libe- rada de 162 hectáreas.

Como oportunidad, las ruinas industriales han permitido el aprovechamiento de espacios, cuyo principal valor lo deben a estar próximos al centro urbano. Uno de estos primeros espacios en ser aprovechado como lugar de esparcimiento fue el Parque Echevarría, en los terrenos que ocupó en otro tiempo la planta siderúrgica del mismo nombre, próxima al Casco Viejo. El desmantelamiento de la estación de mercancías de Amézola, emplazada entre el Ensanche y el barrio de Rekalde dio lugar a una actuación urbana consistente en la construcción de bloques de viviendas alrededor de un nuevo parque. Otro parque más extenso ha sido el de Miraflores, creado sobre antiguas explotaciones mineras en terrenos de los municipios de Basauri y Arrigorriaga. El siguiente proyecto, en fase de realización es el parque de la mina del Morro. Finalmente, un espacio muy codiciado para la reconversión es la península de Zorrozaurre, en la ría de Bilbao. Esta área singular fue creada por la construcción del canal de Deusto no hace muchos años. El canal "peninsulizó" (es decir, aisló parcialmente) a una zona residencial y fabril ribereña previamente existente. Hoy en día su estado de aparente deterioro residencial y fabril le dan un gran valor como reserva de "bilbao beauty". Incluso ofrece la posibilidad -como ya se ha visto en los concursos de ideas de urbanización de la zona- de ser convertida en una isla: la Giudecca de Bilbao.

Más allá del centro urbano, uno de los principales proyectos sobre espacios mineros es la creación de un campo de golf en la margen izquierda de la ría, en la zona de la Arboleda, proyecto impulsado por la Diputación de Bizkaia. El encanto del emplazamiento de la Arboleda: una serie de llanuras elevadas sobre la ría, a las que se accede por una sinuosa carretera, o alternativamente, por funicular, ha sido el de su aparente abandono: pequeños agrupamientos de viviendas mineras realizadas muchas veces con técnicas de autoconstrucción, desmontes, lagos creados por la extracción del mineral del hierro, extensas praderas que sirven de pasto al ganado, etc. Eran varias las décadas en las que la Arboleda mostraba la misma imagen: Iugar en el que el tiempo se había parado, destino de excursiones escolares sin finalidad didáctica, invadido posteriormente por usos marginales y expolio no controlado: lavado de coches, motocross, pasto de ganado, etc. Este final para la Arboleda probablemente dé lugar a protestas por la instalación de un campo de golf, un juego que inventaron los pastores ingleses y que fue traido aquí por algunos descendientes suyos, dueños y explotadores de las mismas minas. No obstante la abundancia de espacios mineros relictos y derelinquidos es tal que garantiza una explotación del "contexto" por muchos años. Hay así, cerca de la Arboleda un "centro de interpretación ambiental" (Peñas Negras), que funciona en realidad como un equipamiento pedagógico, dirigido a introducir a los escolares tanto al medio ambiente de la zona, como al pasado histórico de la minería vizcaína.

La segunda alternativa de regeneración que permite crear un patrimonio cultural son los museos temáticos, a los que se incor- 


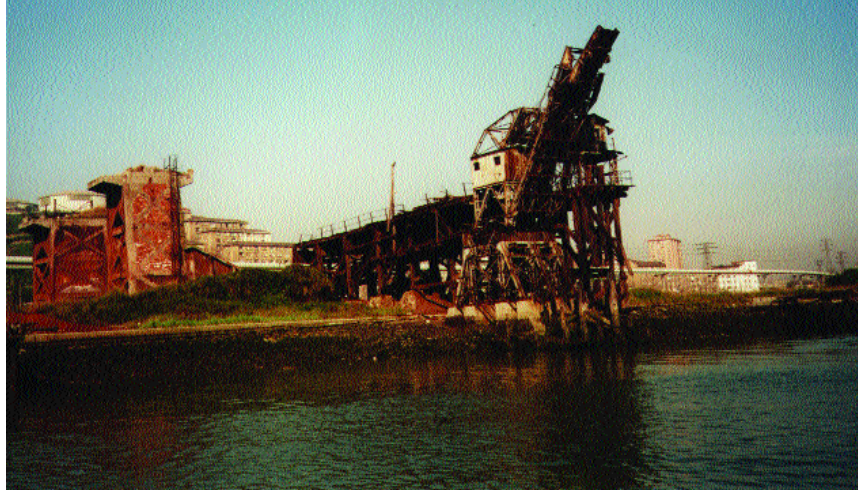

poran materiales que son valorados como dignos de conservación, y que pueden producir renta mediante su exhibición. Son a la vez un depósito de capital cultural y didáctico, pero también una explotación del pasado como destino turístico, según expresión del geógrafo David Lowenthal: el pasado como país extraño (Lowenthal, 1998). A los museos ya existentes en Bilbao, los nombrados de Bellas Artes y Guggenheim, además de otro más antiguo, el Arqueológico y Etnográfico situado en el Casco Viejo, se van a unir algunos nuevos museos: el museo marítimo, en fase avanzada de construcción, y que se encuentra situado en Abandoibarra. Este museo aprovecha las dársenas de la antigua factoría Euskalduna, y algún otro elemento: una de las grandes grúas que funcionó en esos astilleros y un pequeño edificio de sala de las bombas que se utilizaban para vaciar las dársenas de construcción. La creación de este museo ha generado algunos trabajos de restauración de pequeños barcos que formarán su patrimonio: una draga, un gánguil, un barco pesquero, etc.

Lejos de Abandoibarra se preparan otros dos museos temáticos que reflejan simbólicamente otras actividades del pasado de Bilbao: el museo minero y el museo industrial. De momento, el museo minero está situado en un edificio que sirvió de matadero de ganado en el pueblo de Gallarta. El entorno es un paisaje de belleza dura: cerca del escarpe del gran desmonte de la última mina que funcionó en Bizkaia: el pozo de Bodovalle, en las afueras del pueblo que fue la cuna de Dolores Ibarruri, la célebre "Pasionaria". Próximo también al cementerio de la localidad, el museo tiene aún el aspecto del almacén de un vendedor en almoneda, y está rodeado de cachivaches que esperan su museización. Esto revela el origen de este museo en coleccionistas privados, donaciones y grupos voluntarios. Este patrimonio será asumido por las instituciones públicas. El museo de la Industria, cuya ubicación parece que será La Casa del Mar en Portugalete, se encuentra aún en ciernes. Espera recibir gran parte de su patrimonio de las factorias de la empresa más emblemática de Bizkaia, la extinta Altos Hornos de Vizcaya. Existen igualmente otras alternativas de creación de museos aprovechando viejas instalaciones, como por ejemplo, un "museo del agua", ubicado en los edificios de motobombas que enviaban desde Elorrieta las aguas fecales de Bilbao hacia el mar, y que quedaron en desuso con la creación de otras infraestructuras de saneamiento (foto 1). En todo caso, estas nuevas infraestructuras museísticas no suponen un aumento de la oferta de cara al visitante externo. Su lentitud en la puesta en marcha revela que se trata de equipamientos dirigidos al visitante local, ya que el turista (extranjero) que acude a los museos de primer nivel (con varias estrellas en las guías turísticas), según la lógica económica de la industria turística hay que dirigirlo preferentemente a los hoteles con varias estrellas y a los restaurantes con muchos tenedores, antes que a las exhibiciones nostálgicas de la cultura local. Ejemplos que chocan con otras iniciativas un tanto postmodernas como la creación de un museo de automóviles Rolls Royce, por parte de un particular, en Galdames, un antiguo concejo de la zona minera de las Encartaciones, contiguo al área metropolitana de Bilbao.
Foto 2: Cargadero de mineral de la sociedad Franco-Belga, sobre los muelles de la ría, en Baracaldo,

según el aspecto que presentaba el año 1995

Foto 3: El mismo cargadero Restaurado el año 2002 por Bilbao-Ría 2000

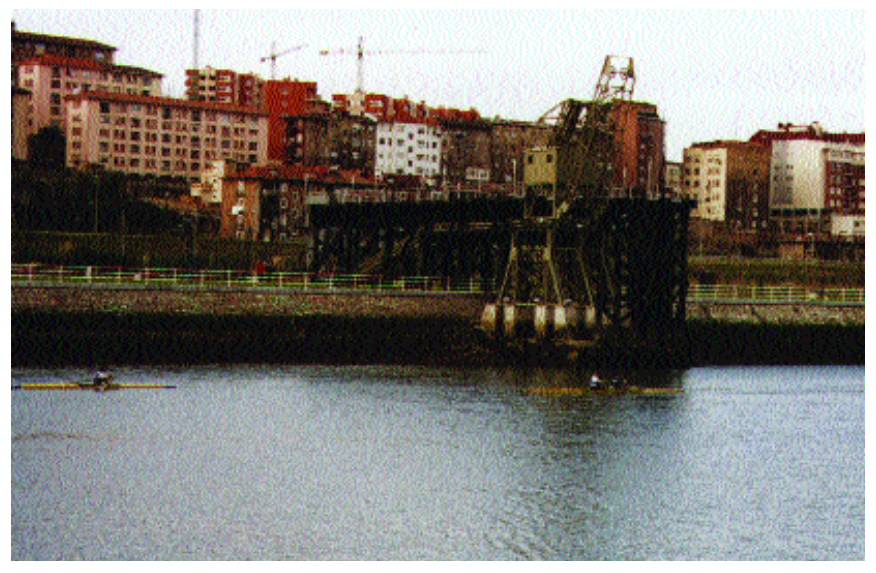

En tercer lugar habria que considerar la conservación de elementos emblemáticos del pasado, que casi siempre son muestras de la técnica y del gigantismo industrial: grúas, chimeneas, altos hornos, etc. Buena parte de estos elementos han sido inventariados por investigadores locales (Villar, 1994). La alternativa para estos elementos, que se conservan por su valor alegórico, es o bien su museización, o bien su utilización parcial en combinación con otros simbolos de la modernidad. En el primero de los casos se produce una pérdida de significado, según la idea clásica de Ruskin, de que conservar es alterar el significado, y también, cuando se trata de muestras del gigantismo industrial plantea el problema del mantenimiento físico, y quién es el que asume los costes de conservación: problema que surge frecuentemente cuando los grupos conservacionistas presionan a los responsables del patrimonio público para que incluyan algunos bienes en sus catálogos de monumentos. Un ejemplo de ello es la declaración de monumento del Horno número 1 de la planta de Altos Hornos de Vizcaya, por parte de la consejería de Cultura del Gobierno Vasco, cuyo propietario actual es la empresa ACB (Acería Compacta de Bizkaia). La alteración del contexto por la conservación y museización puede apreciarse comparando las dos fotografías (fotos 2 y 3 ) del cargadero de mineral de la empresa Franco-Belga en la orilla del Nervión, restaurado por la sociedad Bilbao-Ría 2000 el año 2002. El cambio de significado no se debe sólo a la manipulación de la pieza, sino a los cambios en el entorno: arreglo como paseo del muelle de la ría, construcción de nuevos edificios en el horizonte, y nuevo uso de la ría para actividades deportivas o lúdicas (remo). También hay que considerar que tales elementos tienen su ciclo vital, y que su significado se transmuta. Así, por ejemplo la presencia de una enorme grúa (la grúa Titán) formó parte del paisaje habitual del muelle de Arriluze, en la bahía del Abra, en el municipio de Getxo, desde su construcción a finales del siglo XIX. Durante varias generaciones la grúa fue un objeto inerte, mero simbolo del gigantismo industrial del pasado. En su desmantelamiento el año 1972, las autoridades portuarias decidieron encargar un mural cerámico para recuerdo de este monumento. En la segunda mitad de la década de 1990 se construyó un nuevo puerto de- 


\section{$086-087$}

\section{Debate}

\section{e Investigación}

El Patrimonio histórico

industrial y la revitalización

urbana y económica

de Bilbao

\section{PH42 - Febrero 2003}

portivo y el mural se retiró. Recientemente, algunos vecinos de Getxo echaron en falta el mural, y solicitaron al alcalde de la localidad su reposición. Tras varias gestiones se encontró el mural en unos almacenes del Puerto Autónomo. El municipio asumió la reconstrucción del mural y la reposición de las piezas. Esto puede ser una muestra de cómo la nostalgia impulsa el reciclado de símbolos (foto 4).

Finalmente, cabe la posibilidad de uso de las ruinas recicladas con nuevos propósitos artísticos. En este sentido, una iniciativa que no vio su realización fue un proyecto de colocación de esculturas (creo recordar que eran siluetas de escaladores), obra de un conocido pintor, en una chimenea de gran altura que quedó como testigo de la industria en el ya nombrado Parque Echevarría. Tales iniciativas suelen ser consideradas muchas veces como un trato irónico e irrespetuoso hacia el pasado, pero bien cabe considerar que quizá no es tan irrespetuoso como las alegorías al pasado que hace la arquitectura actual: así, "el último barco que se fabricó en los astilleros Euskalduna" no es otra cosa que el Palacio de Congresos que lleva ese nombre: un buque de hierro para una ría de hierro. De momento, el buque de hierro y el buque de titanio han tenido una botadura exitosa. Para terminar citaremos que el entorno de Bilbao tiene valores estéticos que son demandados por parte de un tipo de turista postmoderno que busca la contradicción de los paisajes y el descubrimiento personal. Este tipo de turismo no puede manejarse de manera convencional, pongamos por caso mediante la creación de parques temáticos o safaris fotográficos. Sin embargo, es bien sabido que también la industria turística explota el sentido del descubrimiento y la sorpresa de una forma sutil: ceremonias nativas para trekkers u otros artilugios. Esta práctica parece que ya está asumida, al menos implícitamente, en el desarrollo estratégico del Bilbao Metropolitano. No obstante, la necesaria conexión del turismo cultural relacionado con el patrimonio necesita de otras infraestructuras cuya carencia ha sido señalada muchas veces: hoteles de precios moderados, un sector hostelero dispuesto a atender a la clientela más allá de las temporadas laborales, etc. Todo ello como parte de un planteamiento más social y cultural del turismo

\section{Bibliografía}

BILBAO METRÓPOLI 30. Ría de Hierro / Burdinezko Itsas Adarra / Iron River. Bilbao: Ediciones Laga, 1993

BILBAO METRÓPOLI 30. Informe de Progreso 2001. Bilbao, 2002

BILBAO RIA 2000: 10 años en la Regeneración del Bilbao Metropolitano. Folleto promocional. S/I, s/f. (Repartido en la prensa local de Bilbao en Noviembre de 2002)

BOUILLOT, J. y BERMILS, B. La gestión stratégique de villes. Entre compétition et coopération. Armand Colin. Paris, 1995

BOURDIEU, P. Outline of a theory of practice. Cambridge: University Press, 1977

\section{Opinión del lector}

\section{Algunos peligros evidentes}

José Manuel Moreno Moreno

Las relaciones entre la recuperación del patrimonio histórico y su conservación a través de su puesta en valor con el desarrollo económico y social de un área geográfica determinada son múltiples. De forma directa, la difusión de ese patrimonio, bien como recurso económico por medio del turismo cultural, bien como factor de dinamización cultural de una localidad a través de las distintas actividades culturales que se planteen aprovechando la recuperación de esos bienes, incide en la propia estructura económica de la población, la cual tiende a la terciarización de sus actividades para dar respuesta a la llegada de nuevos visitantes que requieren unos servicios determinados: infraestructuras de comunicaciones, hoteles, restaurantes, tiendas...; y, por otro lado, a la identificación de esa población con esos bienes patrimoniales, concienciándose de la necesidad de su conservación. Al mismo tiempo, la realización de distintas actividades culturales en esos lugares acerca el tradicionalmete alejado mundo de la cultura a sectores de la población que antes unca lo hubieran considerado como algo atractivo.

En la actualidad, la ciudad de Málaga, por ejemplo, vive inmersa en la asunción de la premisa: patrimonio=desarrollo. La revolución en todos los ámbitos (culturales, sociales, económicos...) que va a suponer para la ciudad la apertura del museo Picasso nos muestra cómo un proyecto cultural de primer orden puede llevar a una población a cambiar, en gran medida, su concepto de desarrollo. Sin embargo, los peligros son evidentes: la sumisión de los otros bienes patrimoniales al proyecto estrella, dejando otras zonas de la ciudad sin el maná turístico; peligro de deterioro del patrimonio ante una avalancha de visitantes hasta ahora no prevista, colapso de las infraes- 
